\title{
Host plant, host plant chemistry and the polyembryonic parasitoid Copidosoma sosares: indirect effects in a tritrophic interaction
}

\author{
Paul J. Ode, May R. Berenbaum, Arthur R. Zangerl and Ian C. W. Hardy
}

\begin{abstract}
Ode, P. J., Berenbaum, M. R., Zangerl, A. R. and Hardy, I. C. W. 2004. Host plant, host plant chemistry and the polyembryonic parasitoid Copidosoma sosares: indirect effects in a tritrophic interaction. - Oikos 104: 388-400.
\end{abstract}

\begin{abstract}
Host plant identity and host plant chemistry have often been shown to influence host finding and acceptance by natural enemies but comparatively less attention has been paid to the tritrophic effects of host plant and host plant chemistry on other natural enemy fitness correlates, such as survivorship, clutch size, body size, and sex ratio. Such studies are central to understanding both the selective impact of plants on natural enemies as well as the potential for reciprocal selective impact of natural enemies on plant traits. We examined the effects of host plant and host plant chemistry in a tritrophic system consisting of three apiaceous plants (Pastinaca sativa, Heracleum sphondylium and H. mantegazzianum), the parsnip webworm (Depressaria pastinacella) and the polyembryonic parasitic wasp Copidosoma sosares. All of these plants produce furanocoumarins, known resistance factors for parsnip webworms. Furanocoumarin concentrations were correlated neither with the presence nor the number of webworms on a given plant. Concentrations of two furanocoumarins were negatively associated with $C$. sosares fitness correlates: isopimpinellin with the likelihood that a given webworm would be parasitized and xanthotoxin with both within-brood survivorship (of all-male and mixed-sex broods) and clutch size. Brood sex ratio and body sizes of individual wasps were not correlated with furanocoumarin chemistry. Because additive genetic variation exists in $P$. sativa for furanocoumarin chemical traits, these are subject to selection by webworms through herbivory. Third trophic level selective impacts on furanocoumarin traits may include selection for reduced production of those chemicals that affect parasitoid survivorship yet do not influence host plant choice by the herbivore. That such might be the case is suggested by patterns of furanocoumarin production in populations of $P$. sativa with different histories of infestation; in the Netherlands, where parasitism rates of webworms by $C$. sosares are high, plants produce lower levels of all linear furanocoumarins and proportionately less isopimpinellin than do midwestern U.S. populations of $P$. sativa, where natural enemies of the webworm are effectively absent.
\end{abstract}

P. J. Ode, Institute of Evolutionary and Ecological Sciences, Univ. of Leiden, NL-2300 RA Leiden, the Netherlands. Present address: Dept of Entomology, North Dakota State Univ., 202 Hultz Hall, 1300 Albrecht Blvd., Fargo, ND 58105, USA (paul.ode@ndsu.nodak.edu)._- M. R. Berenbaum and A. R. Zangerl, Dept of Entomology, Univ. of Illinois at Urbana-Champaign, Urbana, IL 61801, USA. - I. C. W. Hardy, Dept of Ecology and Genetics, Univ. of Arhus, DK-8000 Arhus C, Denmark. Present address: School of Biosciences, Univ. of Nottingham, Sutton Bonington, Loughborough, UK, LE12 5RD.

Plant chemistry can have profound effects on interactions between herbivores and their natural enemies. The majority of tritrophic studies have examined the influ- ence of plant chemistry on host finding and acceptance behavior of foraging natural enemies, in particular parasitic Hymenoptera (Price et al. 1980, Vinson 1984,

Accepted 14 July 2003

Copyright (C) OIKOS 2004

ISSN 0030-1299 
1999, Barbosa and Saunders 1985, Duffey et al. 1986, Price 1986, Barbosa 1988, Nordlund et al. 1988, Turlings et al. 1992, Whitman and Nordlund 1994, De Moraes et al. 1998, Turlings and Benrey 1998, Fukushima et al. 2002, Hoballah et al. 2002). In contrast, few studies have specifically identified tritrophic effects of host plant chemistry on natural enemy fitness correlates such as survivorship, body size, and clutch size (Campbell and Duffey 1979, 1981, Barbosa et al. 1986, 1991, Thorpe and Barbosa 1986, Bourchier 1991, Gauld and Gaston 1994, Roth et al. 1997). Far fewer still are studies investigating whether natural enemies exert a sufficiently strong and consistent impact on herbivores to alter the selective response in plants to herbivory, allowing them to reduce investment in chemical defenses that may be physiologically costly or to change defensive profiles to decrease negative impacts on parasitoids (Hare 1992, Faeth 1994; but see Gómez and Zamora 1994, Stamp and Bowers 1996).

The specific identity of hostplants consumed by herbivorous hosts has long been known to affect the growth and development of parasitoids. Tritrophic effects of plant species (Smith 1957, Altahtawy et al. 1976, Bhatt and Singh 1989, Senrayan and Annadurai 1991, Werren et al. 1992, Fox et al. 1996, Kruse and Raffa 1997, Eben et al. 2000, Harvey et al. 2003, Zvereva and Rank 2003) or cultivar (Kauffman and Flanders 1985, Orr et al. 1985, Hare and Luck 1991, Rogers and Sullivan 1991, Reed et al. 1991, Riggen et al. 1992, Stark et al. 1992) identity have been examined in many studies. Other studies have focused on the tritrophic effects of nitrogen supplementation (Fox et al. 1990, 1996). Although results of these comparative studies are consistent with the notion that variation in chemically based hostplant resistance can lead to differential parasitoid fitness, in only a handful of studies have chemical attributes of hostplants been specifically identified as causative agents influencing parasitoid growth and development.

The limited evidence regarding the tritrophic effects of plant chemistry on parasitoid fitness, other than through facilitating host-finding, suggests that plant chemical defenses generally have a negative impact on natural enemy traits such as development time, survivorship, and body size (Thurston and Fox 1972, Campbell and Duffey 1979, 1981, Barbosa et al. 1986, 1991, ElHeneidy et al. 1988, Thaler 1999). We know of no prior study, however, that has documented a differential effect of host plant chemistry on male and female fitness correlates or on parasitoid sex allocation decisions.

The ability to assess the selective impact of plant chemistry on natural enemies and the potential for selective impacts of natural enemies on plant investment in defensive chemistry is severely restricted by the fact that the selective impact of herbivory on hostplant chemistry has been documented in relatively few systems
(Hare 1992, Marquis 1992). Third trophic level effects of parasitoids, as mediated by their control of herbivore abundance, are unlikely in systems in which the herbivore itself has no selective impact on plant chemistry. One interaction in which selective impacts have been well documented is that between the parsnip webworm Depressaria pastinacella Duponchel (Lepidoptera: Elachisticlae) and the wild parsnip Pastinaca sativa L. (Apiaceae) in eastern North America. Resistance of the wild parsnip to the parsnip webworm is due largely to the presence of furanocoumarins, secondary compounds that are broadly biocidal as a result of their ability to intercalate DNA and interfere with transcription (Berenbaum 1990). As a consumer of reproductive tissues of parsnip, a monocarpic biennial, the parsnip webworm has the capacity to cause substantial fitness reductions in its host plants; in fact, differential damage among parsnip genotypes by webworms results in selection for chemically based resistance in plant populations (Berenbaum et al. 1986, Zangerl and Berenbaum 1990, Zangerl and Rutledge 1996). In turn, genetic variation exists in webworm populations in the efficacy with which different furanocoumarins are metabolized (Berenbaum and Zangerl 1992), indicating that plant chemistry can act as a selective force on insect physiology.

Here we report the results of a field study examining the relationships among host plant allelochemicals, herbivore distributions among host plants, and parasitoid fitness and reproductive behavior. Our system consists of three apiaceous host plant species (wild parsnip, hogweed [Heracleum sphondylium L.], and the giant hogweed [H. mantegazzianum Sommier \& Levier]), the parsnip webworm, and the parasitoid Copidosoma sosares (Walker) (Hymenoptera: Encyrtidae). The interaction between the parsnip webworm and the wild parsnip is effectively ditrophic in eastern North America (see below). In Europe, however, this interaction may be profoundly influenced by the presence of a specialist parasitoid of the webworm, $C$. sosares; we have observed this association in the Netherlands, Denmark and England. An investigation into the tritrophic relationship in Europe can provide insight into the effects of host plant chemistry on parasitoid fitness and reproductive behavior, which in turn may affect the selective impact of the host herbivore on host plant chemistry.

Further, as a preliminary evaluation of the potential third trophic level impacts on plant chemistry, we compared furanocoumarin production by plants in our parasitized European study populations with those in five unparasitized midwestern North American populations. Given the fitness costs to the plant for the production of furanocoumarins (Zangerl and Berenbaum 1997), negative fitness effects of these compounds on $C$. sosares should result in reduced investment in furanocoumarin production in European plants compared to North American plants. Such an analysis, 
although correlative in nature, can provide insights into the impacts of host plant chemistry beyond the second trophic level as well as the potential for parasitoids to act as selective agents on organisms other than their hosts. Because natural enemies are an important component of virtually all plant-herbivore associations, knowledge of the interactions between natural enemies and plant defensive traits is critical for a comprehensive understanding of community structure and function.

\section{Material and methods}

\section{Herbivore and host plants}

The parsnip webworm is an oligophagous associate of apiaceous species in the closely allied genera Pastinaca and Heracleum. The parsnip webworm is native to Europe and was described there first by Duponchel in 1838 (Hodges 1974); in the Netherlands, as is the case elsewhere in Europe, its principal host plants are $P$. sativa, Heracleum sphondylium and H. mantegazzianum. All three species are facultative biennial or perennial monocarpic herbs. $P$. sativa and $H$. sphondylium are native to Eurasia (Sheppard 1991, Menemen and Jury 2001) and H. mantegazzianum is native to the Caucasus in south-west Asia and has become naturalized throughout much of Europe (Tiley et al. 1996). P. sativa was introduced into North America in the seventeenth century and has since become widely naturalized throughout the eastern half of North America, growing primarily in disturbed areas (Nuttall 1818, Fernald 1950). The parsnip webworm was apparently accidentally introduced into North America in the nineteenth century (Bethune 1869), most likely as a consequence of its close association with the economically important $P$. sativa (edible parsnip). Although not native in North America, this plant-herbivore relationship has been most intensively studied there. Female $D$. pastinacella lay their eggs singly on the undersides of the plant leaves, or less frequently on flower stalks (Gorder and Mertins 1984). After hatching, the larvae move toward the floral meristems, where they eventually feed on the buds, flowers, and developing fruits within the umbels (Thompson and Price 1977, Gorder and Mertins 1984, Nitao and Berenbaum 1988, Zangerl and Berenbaum 1992). The feeding larva constructs a web around a portion of the umbel and feeds inside (Berenbaum et al. 1993). Although throughout much of its range in North America its sole host is $P$. sativa, D. pastinacella has colonized the native plant Heracleum lanatum Michx., a congener of several of its European host plants (Berenbaum and Zangerl 1991, Zangerl et al. 2002). Like many other species of Apiaceae, these plants produce an array of furanocoumarins that act as defenses against insect herbivores (Berenbaum 1981).
Depressaria pastinacella is able to specialize on furanocoumarin-containing Pastinaca and Heracleum spp. at least in part because of its extraordinary ability to detoxify furanocoumarins by cytochrome P450mediated metabolism (Nitao 1989, Berenbaum and Zangerl 1992). In eastern North America, parsnip webworms metabolize xanthotoxin, a furanocoumarin abundant in the fruits of its host plants, 10 to 300 times faster than other lepidopterans (Zangerl and Berenbaum 1993). The parsnip webworm metabolizes bergapten and sphondin, also found in the fruits, more slowly than xanthotoxin (Berenbaum and Zangerl 1992); this relative ranking of metabolic activity corresponds well to the relative abundance of these furanocoumarins in the wild parsnips used as host plants (Berenbaum and Zangerl 1998). Among webworm fullsib families, rates of furanocoumarin metabolism can vary as much as threefold; this variation is in part genetically based (Berenbaum and Zangerl 1992). The suitability of an individual host plant for webworm growth is determined in large part by the concentrations of bergapten, xanthotoxin, and sphondin in the umbels (Zangerl and Berenbaum 1993). Within a population, plants with high concentrations of these three furanocoumarins are most frequently free from herbivory. In the absence of webworms, however, plants containing high levels of furanocoumarins produce fewer fruits than those with lower levels of furanocoumarins (Zangerl and Berenbaum 1997) indicating a cost of defense.

\section{The parasitoid}

Populations of $D$. pastinacella in eastern and midwestern North America are largely free of any significant natural enemy pressure. Gorder and Mertins (1984) observed parasitism rates of $2.7 \%$ and $0.8 \%$ in two consecutive years, mostly due to Apanteles depressariae, a solitary endoparasitic braconid, and intensive sampling of webworm populations for over 15 years in east central Illinois has never yielded estimates of parasitism rates in excess of these low percentages (MRB and ARZ, unpubl.). In contrast with eastern and midwestern North American populations, European webworm populations are subject to major mortality by $C$. sosares: rates of attack often exceed $80 \%$. Other parasitoids are known to attack parsnip webworms in the Netherlands, including Macrocentrus bicolor Curtis (Braconidae), Tycherus stipator (Wesmael) (Ichneumonidae), Vulgichneumon lepidus (Gravenhorst) (Ichneumonidae), Pimpla spuria Gravenhorst (Ichneumonidae), and Chorinaeus cristator (Gravenhorst) (Ichneumonidae); however, parasitism rates in excess of $1.5 \%$ have not been recorded (PJO and ICWH, unpubl.).

Like all other copidosomatine encyrtids (Strand et al. 1991), C. sosares is a polyembryonic parasitoid and has 
an extremely narrow host range. Museum specimens of $C$. sosares have been recorded from the larvae of the elachistids Depressaria pastinacella $(=D$. heracliana) and D. nervosa (J. Noyes, pers. comm.). Although the host range of $C$. sosares has not been completely defined, every indication is that it is highly restricted; in many locations $D$. pastinacella appears to be the sole host for $C$. sosares (ICWH and PJO, unpubl.).

Female $C$. sosares oviposit in the egg stage of the host and the progeny complete their development in the final (sixth) instar of the host. The development time of $C$. sosares is approximately 30 days. C. sosares produce three types of broods in the field: all-male, all-female, and mixed-sex (Hardy 1996, PJO and ICWH, unpubl.). All-male and all-female broods are produced by laying a single male or female egg, and mixed-sex broods are produced by laying one male and one female egg per host egg (PJO, unpubl.). During host development, eggs of C. sosares proliferate clonally, ranging from 10 to 300 genetically identical offspring per host (Hardy 1996, this study).

\section{Data collection and furanocoumarin quantification}

We sampled 14 field sites containing $P$. sativa, $H$. sphondylium or $H$. mantegazzianum within the Netherlands from 5 August 1997 to 14 August 1997. All sites were disturbed areas such as roadsides or abandoned land. At each, we randomly selected between 10 and 30 plants that had produced ripened fruit. A total of 262 (35 H. mantegazzianum, 160 H. sphondylium, and 67 P. sativa) plants were carefully searched for all $D$. pastinacella individuals. At these sample dates, nearly all 1463 webworms that we collected were mummies containing C. sosares (640) or pupae. Each webworm larva, pupa and mummy was kept individually in a glass vial plugged with cotton until either an adult moth or adult parasitoids emerged.

We collected approximately 100 mature fruits from the primary umbel of each sampled plant. In some cases, no mature fruits were available for collection either because the majority of mature fruits had dispersed or had been eaten by webworms. Such plants were excluded from the study. The fruits from each plant were dried for three days at $50^{\circ} \mathrm{C}$ and cut in half to expose the oil ducts, which contain furanocoumarins. Furanocoumarins were directly extracted by placing $300 \mathrm{mg}( \pm 10 \mathrm{mg})$ of dried, cut fruits in $1.5 \mathrm{ml}$ of ethyl acetate for one hour. The concentrations of seven furanocoumarins (angelicin, psoralen, xanthotoxin, sphondin, bergapten, isopimpinellin and imperatorin) were analyzed with gas chromatography according to Zangerl et al. (1997). Psoralen, xanthotoxin and bergapten standards were obtained from Sigma (St. Louis, MO); isopimpinellin and angelicin standards were obtained from Indofine (Belle Mead,
New Jersey), and sphondin standards were obtained from Dr. William Wulff (Univ. of Chicago, IL). We compared the furanocoumarin profiles of the three host plant species using multivariate analysis of variance (MANOVA) (PROC GLM; SAS Institute Inc. 19992001). Concentration values for each of the furanocoumarins were log-transformed to achieve normally distributed error variances for this and all subsequent analyses in this study. Throughout this study, we used sequential Bonferroni adjustments to assess the significance of a particular parameter estimate within each multiple regression or logistic regression test.

\section{Ditrophic correlates of furanocoumarin concentration}

We scored each plant for the presence or absence of $D$. pastinacella and, where they were present, counted the number of D. pastinacella (including larvae, pupae and mummies). The effect of host plant species and seed furanocoumarin content on the presence of webworms was tested using logistic regression (PROC LOGISTIC; SAS Institute Inc. 1999-2001). We analyzed the effect of host plant species and furanocoumarin concentration on the number of webworms present with an analysis of covariance (ANCOVA), treating each furanocoumarin as a covariate (PROC GLM; SAS Institute Inc. 19992001). The number of webworms per plant was logtransformed to achieve normally distributed error variances. The size of webworms that successfully pupated (i.e. were not parasitized) was measured by multiplying the length and width of the pupa. Effects of host plant species and furanocoumarin concentration on webworm pupal size were analyzed with an ANCOVA, treating each furanocoumarin as a covariate.

\section{Tritrophic correlates of furanocoumarin concentration}

For each sampled plant, we determined the proportion of webworms present that were parasitized by $C$. sosares. The joint effects of host plant species and concentrations of each of the furanocoumarins on the probability that a given webworm was parasitized were analyzed with logistic regression analysis (PROC LOGISTIC; SAS Institute Inc. 1999-2001).

For each brood of $C$. sosares, we calculated the primary and secondary clutch sizes and sex ratios of each of the three types of broods (all-male, all-female and mixed-sex). Here we follow the terminology used by Ode and Strand (1995); the maternal clutch size and sex ratio refer to the number and sex of the eggs laid by the mother, the primary clutch size and sex ratio refer to the total number of offspring (including embryos, larvae, 
pupae and adults) that develop as a result of polyembryonic divisions, and the secondary clutch size and sex ratio refer to the number and sex of the adult wasps that successfully emerge from a host. Primary and secondary clutch sizes and sex ratios of $C$. sosares are determined by the degree to which male and female eggs divide via polyembryony and may be influenced by variation in host quality including the furanocoumarin content of their hosts and the plants on which they feed. We analyzed the joint effects of host plant species, sexual composition, and furanocoumarin concentrations on primary clutch size with ANCOVA, treating each furanocoumarin as a covariate. The effects of host plant species and furanocoumarin concentrations on secondary sex ratios of mixed-sex broods were analyzed with an ANCOVA with each furanocoumarin as a covariate. Sex ratio values were arcsine square root-transformed before analysis.

Within-brood survivorship was calculated as the secondary clutch size divided by the primary clutch size (the total number of adults that successfully developed divided by the total number of offspring produced). The joint effects of host plant species, sexual composition, and furanocoumarin concentrations on withinbrood survivorship were analyzed with an ANCOVA. Survivorship values were arcsine square root-transformed before analyses.

Body sizes of male and female parasitoids were estimated by measuring the tibial lengths of 10 individuals of each sex (if available) using a stereomicroscope fitted with an ocular micrometer at $60 \times$ magnification. In addition to the possible effects of host plant species and furanocoumarin concentrations, body size is likely to be influenced by the intensity of competition for host resources. Therefore, we included a term for clutch size in our model. The effects of host plant species and furanocoumarin concentrations on average adult male and female body size were analyzed with an ANCOVA, with clutch size and each of the furanocoumarins treated as covariates.

Lastly, we examined the relationship between the proportion of all-male, all-female, and mixed-sex broods that were laid per plant as a function of host plant species and furanocoumarin concentration by logistic regression analysis (PROC LOGISTIC; SAS Institute Inc. 1999-2001). This analysis provides an indication of whether ovipositing females make sex allocation decisions based on furanocoumarin concentrations that may differentially affect their male and female offspring.

\section{Comparison between systems in the Netherlands and the midwestern US}

We analyzed concentrations of furanocoumarins (imperatorin, bergapten, isopimpinellin, xanthotoxin and sphondin) in P. sativa plants from two field sites in the Netherlands (Zwolle and Zoetermeer) and from five midwestern U.S. sites (Charleston, IL; Peotone, IL; St. Louis, MO; Urbana, IL; Winona, MN). These two sites in the Netherlands were used in this comparison because they were the only ones with sufficient numbers of $P$. sativa to allow direct comparison of investment patterns in furanocoumarins by plants in a tritrophic system (the Netherlands) with those in a ditrophic system (midwestern U.S.). Ripe fruits were collected from 25-26 plants in each of the five midwestern populations and furanocoumarins were extracted as described earlier. Extracts were analyzed by high pressure liquid chromatography according to Berenbaum and Zangerl (1998). We compared the furanocoumarin profiles of $P$. sativa from the two sites in the Netherlands with the five sites in the midwestern U.S. with a MANOVA (PROC GLM: SAS Institute Inc. 1999-2001).

\section{Results}

The three host plant species differed significantly in terms of their furanocoumarin profiles (overall: Roy's Greatest $\operatorname{Root}=4.13, \mathrm{~F}_{6,185}=127.43, \mathrm{P}<0.0001 ; H$. mantegazzianum vs $H$. sphondylium: Roy's Greatest Root $=3.55, \mathrm{~F}_{6,184}=108.75, \mathrm{P}<0.0001 ; H$. mantegazzianum vs $P$. sativa: Roy's Greatest $\mathrm{Root}=4.08, \mathrm{~F}_{6,184}=$ 125.22, $\mathrm{P}<0.0001 ; H$. sphondylium vs $P$. sativa: Roy's Greatest Root $\left.=3.42, \mathrm{~F}_{6,184}=104.98, \mathrm{P}<0.0001\right)$. Heracleum mantegazzianum fruits contained the highest levels of angelicin, psoralen and isopimpinellin; $H$. sphondylium fruits contained the highest levels of bergapten; $P$. sativa fruits contained the highest levels of xanthotoxin; H. sphondylium fruits contained the lowest total furanocoumarin content of the three plant species (Table 1). Qualitatively, H. mantegazzianum differed from the other two species in lacking sphondin. Results of the univariate comparisons of individual furanocoumarin content as well as total furanocoumarin content differences among host plant species are presented in Table 1.

\section{Ditrophic correlates of furanocoumarin concentration}

Heracleum sphondylium was more likely to be attacked by $D$. pastinacella than either $H$. mantegazzianum or $P$. sativa (Wald $\chi^{2}=11.93, \mathrm{df}=2, \mathrm{P}=0.0026$, Table 2 ). $H$. mantegazzianum and $P$. sativa were equally likely to be attacked by $D$. pastinacella (Wald $\chi^{2}=3.54, \mathrm{df}=1, \mathrm{P}=$ 0.0599). After the effect of host plant species was taken into account, none of the seven furanocoumarins was significantly associated with the presence or absence of webworms on a given plant ( $\mathrm{P}$-values for Wald $\chi^{2}>0.20$ 
Table 1. Differences in furanocoumarin concentrations (ng/mg \pm s.e.m.) among the three host plant species for Depressaria pastinacella in the 14 sites the Netherlands. Reported ANOVA P-values are from the univariate tests of host plant differences for individual furanocoumarins. Within a row, furanocoumarin concentrations with the same letter are not significantly different from one another using sequential Bonferroni t-tests. Furanocoumarin concentrations were recorded from $34 \mathrm{H}$. mantegazzianum (with the exception of sphondin, which was recorded in no plants), $111 \mathrm{H}$. sphondylium (with the exception of sphondin, which was recorded in 35 plants), and $48 P$. sativa (with the exception of sphondin, which was recorded from 14 plants).

\begin{tabular}{lccrc}
\hline Furanocoumarin & \multicolumn{3}{c}{ Host plant species } & ANOVA P \\
\cline { 2 - 4 } & H. mantegazzianum & H. sphondylium & P. sativa & \\
\hline angelicin & $8536.72 \pm 496.76^{\mathrm{a}}$ & $29.40 \pm 4.63^{\mathrm{b}}$ & $3.07 \pm 2.41^{\mathrm{c}}$ & $<0.0001$ \\
bergapten & $3237.69 \pm 247.51^{\mathrm{b}}$ & $4055.48 \pm 146.28^{\mathrm{a}}$ & $2185.25 \pm 180.82^{\mathrm{c}}$ & $<0.0001$ \\
imperatorin & $676.58 \pm 49.60^{\mathrm{a}}$ & $208.55 \pm 12.88^{\mathrm{b}}$ & $938.81 \pm 90.16^{\mathrm{a}}$ & $<0.0001$ \\
isopimpinellin & $997.21 \pm 91.85^{\mathrm{a}}$ & $178.57 \pm 13.49^{\mathrm{c}}$ & $298.39 \pm 31.24^{\mathrm{b}}$ & $<0.0001$ \\
psoralen & $693.02 \pm 68.61^{\mathrm{a}}$ & $22.10 \pm 3.61^{\mathrm{b}}$ & $27.59 \pm 10.55^{\mathrm{b}}$ & $<0.0001$ \\
sphondin & - & $222.19 \pm 45.63$ & $455.12 \pm 217.41$ & 0.1360 \\
xanthotoxin & $1137.11 \pm 127.34^{\mathrm{b}}$ & $258.89 \pm 27.25^{\mathrm{c}}$ & $2709.30 \pm 220.57^{\mathrm{a}}$ & $<0.0001$ \\
Total furanocoumarins & $15278.32 \pm 859.41^{\mathrm{a}}$ & $4822.85 \pm 164.48^{\mathrm{b}}$ & $6295.16 \pm 484.00^{\mathrm{b}}$ & $<0.0001$ \\
\hline
\end{tabular}

for each furanocoumarin). After accounting for furanocoumarin content, $H$. sphondylium plants harbored more webworms than did either $P$. sativa or $H$. mantegazzianum (partial- $\mathrm{F}_{1,154}=15.41, \mathrm{P}<0.0001$; Table 2), despite the fact that $H$. mantegazzianum is typically the largest of the three species and $P$. sativa the smallest in terms of plant size. H. mantegazzianum and $P$. sativa did not differ in average number of webworms harbored after accounting for furanocoumarin content (partial- $\mathrm{F}_{1,154}=0.29, \mathrm{P}=0.5882$; Table 2). Once the effect of host plant species was taken into account, amounts of none of the seven furanocoumarins were significantly correlated with the number of webworms present per plant (P-values for type III SS partial$F$ statistics $>0.25$ for each furanocoumarin). Neither host plant species (partial- $\mathrm{F}_{1,51}=1.07, \mathrm{P}=0.31$ ) nor any of the individual furanocoumarins was significantly correlated with the size of unparasitized webworm pupae
(P-values for type III partial-F statistics $>0.15$ in all cases).

\section{Tritrophic correlates of furanocoumarin concentration}

The probability that a given webworm would be parasitized was significantly associated with host plant species (Wald $\chi^{2}=15.98, \mathrm{P}=0.0003 ; H$. sphondylium $<$ P. sativa $=H$. mantegazzianum, Table 2). After the effect of host plant species and the other furanocoumarins were accounted for, isopimpinellin content alone was negatively correlated with the probability that a given webworm would be parasitized (Wald $\chi^{2}=7.09, \mathrm{P}=$ 0.0078 ; P-values for Wald $\chi^{2}=>0.4$ for all other furanocoumarins, except for imperatorin: Wald $\chi^{2}=$ $3.19, \mathrm{P}=0.0742$ ).

Table 2. Ditrophic host plant species effects on presence and numbers of webworms ( \pm s.e.m.) and tritrophic effects on clutch size $(+$ s.e.m.) and survivorship ( \pm s.e.m.) of all-male, all-female, and mixed sex broods and sex ratio of mixed sex broods of $C$. sosares. Within a row, values with different superscript letters are significantly different using sequential Bonferroni-adjusted linear contrast tests; those with the same or no superscript letter are not significantly different. Linear contrasts comparing differences among the three host plant species were constructed after accounting for log-transformed covariate (furanocoumarin) effects (see text for details).

\begin{tabular}{|c|c|c|c|}
\hline \multirow[t]{2}{*}{ Trait } & \multicolumn{3}{|c|}{ Host plant species } \\
\hline & H. mantegazzianum & H. sphondylium & P. sativa \\
\hline \multicolumn{4}{|l|}{ Depressaria pastinacella: } \\
\hline Plants with webworms/total plants & $10 / 35^{\mathrm{b}}$ & $144 / 160^{\mathrm{a}}$ & $32 / 67^{\mathrm{b}}$ \\
\hline Mean number webworms & $1.60 \pm 0.22^{\mathrm{b}}$ & $12.75 \pm 1.49^{\mathrm{a}}$ & $3.04 \pm 0.86^{\mathrm{b}}$ \\
\hline \multicolumn{4}{|l|}{ Copidosoma sosares: } \\
\hline Mean percent parasitized & $66.67 \pm 14.91^{\mathrm{a}}$ & $43.76 \pm 3.43^{\mathrm{b}}$ & $78.06 \pm 8.01^{\mathrm{a}}$ \\
\hline Mean clutch size: all-male & $161.5 \pm 33.58$ & $236.73 \pm 6.34$ & $224.83 \pm 25.15$ \\
\hline all-female & $140.85 \pm 14.75$ & $163.57 \pm 4.14$ & $135.63 \pm 13.75$ \\
\hline mixed-sex & $173 \pm 50$ & $193.36 \pm 13.75$ & $218.87 \pm 18.90$ \\
\hline Mean survivorship (\%): all-male & $76.30 \pm 6.25$ & $74.23 \pm 2.89$ & $45.2 \pm 17.54$ \\
\hline all-female & $65.82 \pm 22.31$ & $75.09 \pm 2.24$ & $71.19 \pm 7.94$ \\
\hline mixed-sex & $65.25 \pm 0.21$ & $75.14 \pm 4.01$ & $51.36 \pm 9.26$ \\
\hline Mean sex ratio (\%) & $76.23 \pm 19.27$ & $49.68 \pm 6.10$ & $67.89 \pm 3.61$ \\
\hline Total furanocoumarins & $15278.32 \pm 859.41^{\mathrm{a}}$ & $4822.85 \pm 164.48^{\mathrm{b}}$ & $6295.16 \pm 484.00^{\mathrm{b}}$ \\
\hline
\end{tabular}


After accounting for the effects of host plant species and furanocoumarin concentrations, clutch sizes of allmale broods were significantly greater than all-female broods (linear contrast $\mathrm{F}_{1,86}=10.68, \mathrm{P}=0.0016$ ); clutch sizes of mixed-sex broods were intermediate and not significantly different from clutch sizes of either all-male or all-female broods (vs all-male broods: linear contrast $\mathrm{F}_{1,86}=1.76, \mathrm{P}=0.1878$; vs all-female broods: linear contrast $\mathrm{F}_{1,86}=2.62, \mathrm{P}=0.1091$, Table 2). C. sosares clutch size was not affected by host plant species (partial- $\mathrm{F}_{2,86}=0.48, \quad \mathrm{P}=0.6204$ ) after brood sexual composition and furanocoumarin concentrations were taken into account. After host plant species and sexual composition of $C$. sosares brood had been taken into account, only xanthotoxin concentration was negatively correlated with clutch size (partial- $\mathrm{F}_{1,86}=12.89, \mathrm{P}=$ 0.0005; P-values for partial-F statistics exceeded 0.15 for all other furanocoumarins). Xanthotoxin concentration affected similarly all three types of $C$. sosares broods (xanthotoxin $\times$ sex interaction term: partial$\left.\mathrm{F}_{2,86}=1.74, \mathrm{P}=0.1820\right)$.

Secondary sex ratios of mixed-sex broods were not correlated with host plant species (type III partial- $\mathrm{F}_{2,9}=$ $0.41, \mathrm{P}=0.6728$ ) or with any of the furanocoumarin concentrations ( $\mathrm{P}$ for type III partial F-values $>0.30$ in all cases).

Once the effects of host plant species and sexual composition were accounted for, only xanthotoxin was significantly correlated with parasitoid survivorship (partial- $\mathrm{F}_{1,86}=18.55, \mathrm{P}<0.0001 ; \mathrm{P}$-values for partial-F statistics exceeded 0.25 for all other furanocoumarins except angelicin whose partial- $\mathrm{F}_{1,86}=3.32, \mathrm{P}=0.0718$ ). Furthermore, survivorship of all-male, all-female, and mixed-sex broods were differentially correlated with the concentration of xanthotoxin in fruits (xanthotoxin $\times$ survivorship interaction term: partial- $\mathrm{F}_{1,86}=5.81, \mathrm{P}=$ 0.0043). Whereas xanthotoxin concentration had a negative effect on survivorship of all-male and mixed sex broods (all-male: parameter estimate $\mathrm{t}$-value $=$ $-4.29, \mathrm{P}<0.0001$; mixed-sex: parameter estimate $\mathrm{t}-$ value $=-3.62, \quad P=0.0005)$, survivorship within allfemale broods was not affected by xanthotoxin concentration (parameter estimate $\mathrm{t}$-value $=-1.41, \quad \mathrm{P}=$ $0.1624)$.

After accounting for host plant species effects, female body size was significantly smaller in larger clutches (partial- $\mathrm{F}_{1,34}=8.15, \mathrm{P}=0.0073$ ) but unaffected by furanocoumarin concentrations (P-values for partial Fstatistics were $>0.10$ for all furanocoumarins). Male body size was not correlated with clutch size $\left(\mathrm{F}_{1,23}=\right.$ $0.79, \mathrm{P}=0.3845)$ nor with any of the furanocoumarins ( $P>0.10$ in all cases). After adjusting for host plant species, clutch size, and furanocoumarin content effects, females were significantly larger than males (partial$\left.\mathrm{F}_{1,58}=161.87, \mathrm{P}<0.0001\right)$.
Finally, the proportion of all-male, all-female, and mixed-sex broods per individual host plant was not associated either with the host plant species ( $\operatorname{Pr}>$ type III Wald $\chi^{2}=0.1134$ ) or with concentrations of any of the furanocoumarins ( $\mathrm{Pr}>$ type III Wald $\chi^{2}>0.05$ for all furanocoumarins).

\section{Comparison between systems in the Netherlands and the midwestern US}

Compared to the five midwestern U.S. field populations, parsnip fruits from the two field sites in the Netherlands contained significantly lower concentrations of furanocoumarins (Roy's Greatest Root $=0.72, F_{5,153}=22.03$, $\mathrm{P}<0.0001$, Fig. 1). With the exception of sphondin, parsnip fruits from the Netherlands contained significantly lower concentrations of each of the furanocoumarins as well as total furanocoumarin content than fruits from midwestern U.S. populations (Fig. 1, Table 3). In populations from the Netherlands, isopimpinellin makes up a smaller proportion of total seed furanocoumarin content than in midwestern U.S. populations (Fig. 2, Table 3). On the other hand, while significant variation exists among populations in xanthotoxin content, xanthotoxin as a proportion of total furanocoumarin content did not differ between the Netherlands and midwestern U.S. populations (Table 3). Results of the univariate comparisons of differences in individual furanocoumarin content, total furanocoumarin content, and the proportional contribution of isopimpinellin and xanthotoxin among seven field sites are presented in Table 3.

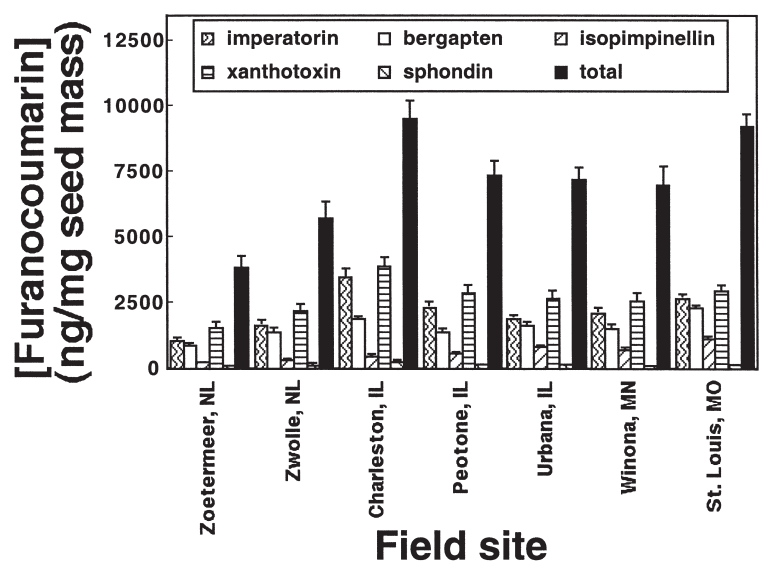

Fig. 1. Mean (+s.e.m.) furanocoumarin concentrations (ng/ $\mathrm{mg}$ ) of the following furanocoumarins from $P$. sativa: imperatorin, bergapten, isopimpinellin, xanthotoxin, sphondin, and total furanocoumarins. From left to right, data are presented from two field sites in the Netherlands [Zwolle $(\mathrm{N}=15)$ and Zoetermeer $(\mathrm{N}=20)$ ] and five in the midwestern U.S. [(in alphabetical order by state) Charleston, IL $(\mathrm{N}=26)$; Peotone, IL ( $\mathrm{N}=26)$; Urbana, IL $(\mathrm{N}=26)$; Winona, $\mathrm{MN}(\mathrm{N}=25)$; and St. Louis, MO $(\mathrm{N}=26)]$. 
Table 3. Results of univariate analysis of variance for furanocoumarin concentration differences in $P$. sativa across all seven field sites (Zwolle, NL; Zoetermeer, NL; Charleston, IL; Peotone, IL; St. Louis, MO; Urbana, IL; and Winona, MN, df =6, 157) and contrasting the furanocoumarin concentration differences between the two sites in the Netherlands with the five sites in the midwestern U.S. $(\mathrm{df}=1,157)$. Univariate tests are reported for xanthotoxin, sphondin, bergapten, isopimpinellin, imperatorin and total furanocoumarin concentrations. In addition, analysis of variance results are presented for the fraction of total furanocoumarin content that is either xanthotoxin or isopimpinellin.

\begin{tabular}{|c|c|c|c|c|c|c|}
\hline \multirow[t]{2}{*}{ Furanocoumarin } & \multicolumn{3}{|c|}{ Across all 7 sites } & \multicolumn{3}{|c|}{ The Netherlands ( 2 sites) vs Midwest U.S. ( 5 sites) } \\
\hline & Type III SS & F value & $\operatorname{Pr}>\mathrm{F}$ & Contrast SS & $\mathrm{F}$ value & $\operatorname{Pr}>\mathrm{F}$ \\
\hline xanthotoxin & 12.93 & 6.88 & $<0.0001$ & 6.24 & 19.90 & $<0.0001$ \\
\hline sphondin & 23.85 & 3.70 & 0.0018 & 0.30 & 0.28 & 0.5994 \\
\hline bergapten & 14.29 & 13.78 & $<0.0001$ & 6.04 & 34.94 & $<0.0001$ \\
\hline isopimpinellin & 45.26 & 27.54 & $<0.0001$ & 24.81 & 90.58 & $<0.0001$ \\
\hline imperatorin & 21.49 & 14.97 & $<0.0001$ & 11.45 & 47.88 & $<0.0001$ \\
\hline total fc & 14.46 & 13.39 & $<0.0001$ & 8.67 & 48.12 & $<0.0001$ \\
\hline prop. xanthotoxin & 0.17 & 2.36 & 0.0330 & 0.01 & 1.17 & 0.2806 \\
\hline prop. isopimpinellin & 0.13 & 24.93 & $<0.0001$ & 0.04 & 40.85 & $<0.0001$ \\
\hline
\end{tabular}

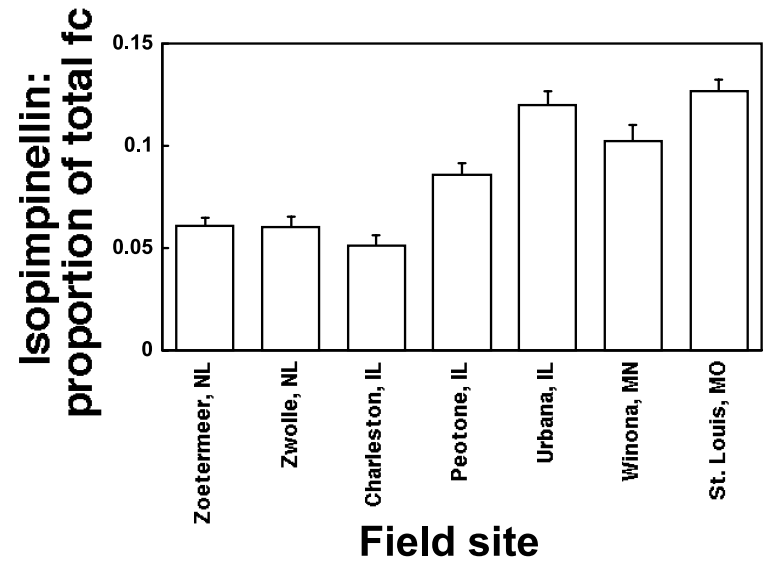

Fig. 2. Mean (+s.e.m.) proportion of total furanocoumarin content that is isopimpinellin in $P$. sativa fruits across seven field sites from the Netherlands and the midwestern U.S. (see Fig. 1 legend for sample sizes from each site). Field sites of differed significantly in terms of the proportion of total furanocoumarin content that was comprised of isopimpinellin. In parsnip plants from the two Dutch sites, isopimpinellin comprised a significantly smaller fraction of total furanocoumarin production as compared to the five midwestern North American sites.

\section{Discussion}

In the tritrophic interaction between Depressaria pastinacella, its apiaceous hostplants, and its parasitoid enemy, host plant identity and variation in secondary chemistry had a demonstrable association with third trophic level fitness measures. Webworms feeding on plants rich in isopimpinellin were less likely to be successfully parasitized by $C$. sosares. Isopimpinellin may have a deterrent effect on ovipositing $C$. sosares females or higher concentrations of isopimpinellin may be lethal to $C$. sosares broods early in development. Additionally, C. sosares broods are affected strongly by the concentration of xanthotoxin in the fruits on which their hosts feed. All-male and mixed-sex C. sosares brood types exhibited lower survivorship and all three brood types exhibited smaller clutch sizes when they develop in hosts that fed on plants rich in xanthotoxin. This pattern suggests that, although webworms are able to detoxify much of the xanthotoxin they encounter while feeding on host plant fruits and floral parts, some xanthotoxin accumulates in webworm tissues where it is encountered by developing $C$. sosares embryos and larvae. Alternatively, webworms feeding on fruits with higher xanthotoxin content may be lower-quality hosts as a consequence of having to allocate greater amounts of energy and resources to detoxify higher quantities of xanthotoxin (Berenbaum and Zangerl 1992) or as a consequence of experiencing chronic furanocoumarin toxicity.

Survivorship of all-female broods, on the other hand, is not affected adversely by high concentrations of xanthotoxin in their host plants. Female embryos and/ or larvae may be more efficient at xanthotoxin detoxification, more tolerant of xanthotoxin, or better able to thrive in a stressed host. Sex-specific effects of furanocoumarins on insects were first demonstrated by Berenbaum and Feeny (1981), who showed that angelicin selectively reduces the growth rate and fertility of females of the swallowtail butterfly Papilio polyxenes in comparison with males. Several studies have demonstrated that host plant species or cultivar identity influences the proportion of emerging female parasitoids (Hare and Luck 1991, Reed et al. 1991, Kruse and Raffa 1997, Eben et al. 2000) and, in some, differences in chemistry have been documented between different host plant species (Harvey et al. 2003). Nitrogen supplementation of host plants has also been shown to result in more female-biased parasitoid sex ratios (Fox et al. 1990, 1996), possibly because of associated changes in host plant chemistry. That host plant chemistry may differentially affect male and female parasitoids is also suggested by several studies of sex-specific toxicological effects of pesticides, which have shown that males are more susceptible to pesticides than are females (Adams and Cross 1967, Lingren et al. 1972, Lasota and Kok 
1986, Scott and Rutz 1988, Rathman et al. 1992, but see $\mathrm{Xu}$ et al. 2001). Our study, however, provides the first evidence of sex-specific tritrophic effects of furanocoumarins (or, indeed, any host plant chemical). In view of these patterns, ovipositing $C$. sosares females might be expected to lay a higher proportion of male eggs in host eggs located on plants with lower concentrations of xanthotoxin. However, we found no evidence to suggest that ovipositing females preferentially allocate male eggs to plants that will eventually produce lower concentrations of xanthotoxin in their fruits. There are several possible explanations for the absence of an association between xanthotoxin content and allocation of male eggs. First, although the observed distribution of brood types across individual host plants may reflect the decisions made by individual foraging females, they may also reflect the oviposition decisions of a group of foundresses, each with different ovipositional experiences and sex allocation decisions. Some females may be constrained to lay only male eggs because they are unmated or have become depleted of sperm. Alternatively, ovipositing females, which oviposit in host eggs that are located on foliage, cannot predict the furanocoumarin profiles that their offspring will encounter in hosts that will feed on fruits not yet present. Such a lack of correlation between oviposition decisions and larval performance has been repeatedly documented in many herbivorous insects (Thompson 1988, Thompson and Pellmyr 1990, Larsson and Ekbom 1995). Indeed, even female $D$. pastinacella lays its eggs on foliage of $P$. sativa in a manner that is independent of furanocoumarin chemistry (Zangerl and Berenbaum 1992).

Previous work suggests that a congener, $C$. floridanum ( $=$ C. truncatellum $)$, is negatively affected by host plant chemistry. Two studies examining the tritrophic effects of resistant soybean cultivars found that $C$. floridanum broods reared soybean loopers, Pseudoplusia includens, fed a resistant variety of soybean experienced longer development times, higher levels of mortality, and reduced numbers of emerging adult offspring (Orr and Boethel 1985, Beach and Todd 1986). Although the mechanism of resistance was not identified in either study, resistance was possibly based on increased levels of plant defensive chemistry. As well, evidence from a study on C. floridanum developing in the cabbage looper, Trichoplusia $n i$, suggests that higher furanocoumarin concentrations result in increased parasitoid mortality (Reitz and Trumble 1996). Fewer adult C. floridanum emerged from broods developing in $T$. $n i$ fed an artificial diet containing high levels of three furanocoumarins (psoralen, xanthotoxin and bergapten) compared to diets with lower furanocoumarin concentrations. Being highly polyphagous, $T$. $n i$ feeds on a wide variety of plants that are devoid of furanocoumarins (Berenbaum and Zangerl 1996). Thus, it is likely that, in nature, $C$. floridanum is rarely exposed to furanocoumarins. In contrast, $C$. sosares is known only from hosts that feed on furanocoumarin-containing plants; moreover, these hosts feed almost exclusively on reproductive structures, which contain up to ten-fold higher concentrations of furanocoumarins than does foliage (Berenbaum and Zangerl 1996). Thus, by virtue of differences in their evolutionary histories, responses of these two Copidosoma species to the presence of furanocoumarins in their hosts might be expected to differ.

\section{Reciprocal tritrophic effects?}

The notion that natural enemies function as an extension of plant defenses, first clearly proposed by Price et al. (1980), is based on the premise that the presence of natural enemies results in a significant reduction in herbivore selective pressure on plants. If defenses incur a large investment cost to parsnip plants, parsnips growing in locations where parasitism rates are high enough to reduce the impact of chronic herbivory should invest less in furanocoumarin-based defenses. Several lines of evidence suggest that this chemical defense is costly to the plant. In greenhouse populations, where herbivory is absent, potential seed production was negatively correlated with the concentration of bergapten (Berenbaum et al. 1986). And in field populations, each $\mathrm{mg} / \mathrm{g}$ increase in furanocoumarin concentration in fruits is accompanied by a $37 \mathrm{mg}$ reduction in seed biomass when herbivores are absent (Zangerl and Berenbaum 1997). Furanocoumarin production in parsnip foliage is also costly, accounting for increased rates of respiration and partially accounting for declines in net photosynthesis (Zangerl et al. 1997). Because additive genetic variation exists in P. sativa for furanocoumarin chemical traits, at least in the midwestern U.S. (Berenbaum et al. 1986), these traits are potentially available for selection. In fact, selective responses to webworm herbivory have been demonstrated experimentally (Berenbaum et al. 1986, Zangerl and Berenbaum 1997).

Third trophic level selective impacts on furanocoumarin chemical traits may include selection for reduced production of metabolically costly resistance compounds (such as sphondin; Zangerl and Berenbaum 1997) due to decreases in herbivory, or for reduced production of those chemicals that affect parasitoid survivorship or sex allocation (such as xanthotoxin and isopimpinellin) yet do not influence host plant choice by the herbivore. Indeed, our comparison of furanocoumarin content of parsnip plants from the Netherlands, where $C$. sosares is common, with plants from the Midwest U.S., where $C$. sosares is absent, suggests that the presence of this parasitoid may select for reduced investment in furanocoumarins. Moreover, compared to midwestern U.S. populations, parsnips from the Netherlands invest proportionally less in isopimpinellin (but not xantho- 
toxin) production relative to the other furanocoumarins. As noted, isopimpinellin negatively affects $C$. sosares; consequently, wild parsnips may have been selected to reduce production of this compound in the presence of C. sosares, particularly if the parasitoid reduces chronic levels of herbivory experienced by subsequent generations of wild parsnip. Furthermore, xanthotoxin responses to presumed selection by $C$. sosares may be constrained by the fact that its production is genetically correlated with that of bergapten, a key resistance factor against parsnip webworms (Berenbaum et al. 1986).

The observed differences between continents might be due in part to other factors (e.g. differences in edaphic conditions, climatic conditions, or evolutionary histories between populations in the Netherlands and the midwestern U.S.), including a clinal reduction in isopimpinellin with latitude in the Midwest (Zangerl and Berenbaum 2003); as all of the Midwest U.S. populations were south of our sites in the Netherlands, differences in isopimpinellin content could simply be due to differences in latitude. Clearly more carefully controlled studies, such as common garden experiments, are warranted in order to fully understand the differences we have observed between the European and North American parsnip, webworm, and $C$. sosares systems.

This tritrophic interaction thus provides insight into the oft-raised possibility that, even though they do not actually consume plant tissue, parasitoids and other natural enemies have the potential to act as selective agents on plant chemistry (Sabelis and de Jong 1988, Whitman 1988, Dicke et al. 1990a,b, Whitman and Nordlund 1994, Turlings et al. 1995, Takabayashi and Dicke 1996, Turlings and Benrey 1998, Vinson 1999, van Loon et al. 2000, Elliot et al. 2000, Kessler and Baldwin 2001). Whether these third trophic level effects are widespread remains to be determined; if they are, they may have important implications not only for understanding the evolution of chemical defense in plants but also for designing pest management approaches integrating biological control and host plant resistance.

Acknowledgements - We thank Jacques van Alphen and E. Davis Parker for providing logistical support and advice, Lieuwe Dijkstra and Henk Nell for helping with location of Dutch field sites and John Noyes, Mark Shaw, and Robert Wharton for taxonomic identifications. This research was supported by USA NSF - NATO Postdoctoral Fellowship grant DGE-9633975 (to PJO), NSF-IBN 0321028 (to PJO and MRB), Commission of European Communities Research Training Grant ERBFMBICT 961025 (to ICWH) and National Science Foundation DEB 9903867 (to MRB and ARZ).

\section{References}

Adams, C. H. and Cross, W. H. 1967. Insecticide resistance in Bracon mellitor, a parasite of the boll weevil. - J. Econ. Entomol. 60: 1016-1020.

Altahtawy, M. M., Hammad, S. M. and Hegazi, E. M. 1976. Studies on the dependence of Microplitis rufiventris Kok.
(Hym., Braconidae) parasitizing Spodoptera littoralis (Boisd.) on own food as on food of its host. - Zeit. Ange. Entomol. 81: 3-13.

Barbosa, P. 1988. Natural enemies and herbivore plant interactions: influence of plant allelochemicals and host specificity.

- In: Barbosa, P. and le Tourneau, D. K. (eds), Novel aspects of insect-plant interactions. John Wiley \& Sons, pp. 201-229.

Barbosa, P. and Saunders, J. 1985. Plant allelochemicals: linkages between herbivores and their natural enemies. - In: Cooper-Driver, G. A., Swain, T. and Conn, E. E. (eds), Chemically mediated interactions between plants and other organisms. Plenum, pp. 107-138.

Barbosa, P., Saunders, J. A., Kemper, J. et al. 1986. Plant allelochemicals and insect parasitoids: effects of nicotine on Cotesia congregata (Say) (Hymenoptera: Braconidae) and Hyposoter annulipes (Cresson) (Hymenoptera: Ichneumonidae). - J. Chem. Ecol. 12: 1319-1328.

Barbosa, P., Gross, P. and Kemper, J. 1991. Influence of plant allelochemicals on the tobacco hornworm and its parasitoid, Cotesia congregata. - Ecology 72: 1567-1575.

Beach, R. M. and Todd, J. W. 1986. Foliage consumption and larval development of parasitized and unparasitized soybean looper, Pseudoplusia includens [Lep.: Noctuidae], reared on a resistant soybean genotype and effects on an associated parasitoid, Copidosoma truncatellum [Hym.: Encyrtidae]. - Entomophaga 31: 237-242.

Berenbaum, M. R. 1981. Patterns of furanocoumarin distribution and insect herbivory in the Umbelliferae: plant chemistry and community structure. - Ecology 62: 12541266.

Berenbaum, M. R. 1990. Evolution of specialization in insectumbellifer associations. - Annu. Rev. Entomol. 35: 319343.

Berenbaum, M. R. and Feeny, P. 1981. Toxicity of angular furanocoumarins to swallowtails: escalation in the coevolutionary arms race. - Science 212: 927-929.

Berenbaum, M. R. and Zangerl, A. R. 1991. Acquisition of a native hostplant by an introduced oligophagous herbivore. - Oikos 62: 153-159.

Berenbaum, M. R. and Zangerl, A. R. 1992. Genetics of physiological and behavioral resistance to host furanocoumarins in the parsnip webworm. - Evolution 46: 13731384.

Berenbaum, M. R. and Zangerl, A. R. 1996. Phytochemical diversity: adaptation or random variation? - Rec. Adv. Phytochem. 30: 1-24.

Berenbaum, M. R. and Zangerl, A. R. 1998. Chemical phenotype matching between a plant and its insect herbivore. - Proc. Natl Acad. Sci., USA 95: 13743-13748.

Berenbaum, M. R., Zangerl, A. R. and Nitao, J. K. 1986. Constraints on chemical coevolution: wild parsnips and the parsnip webworm. - Evolution 40: 1215-1228.

Berenbaum, M. R., Green, E. S. and Zangerl, A. R. 1993. Web costs and web defense in the parsnip webworm (Lepidoptera: Oecophoridae). - Environ. Entomol. 22: 791-795.

Bethune, C. J. S. 1869. Larva infesting the parsnip. - Can. Entomol. 2: 1-4.

Bhatt, N. and Singh, R. 1989. Bionomics of an aphidiid parasitoid Trioxys indicus. 30. Effect of host plants on reproductive and developmental factors. - Biol. Agric. Hort. 6: 149-157.

Bourchier, R. S. 1991. Growth and development of Compsilura concinnata (Meigan) (Diptera: Tachinidae) parasitizing gypsy moth larvae feeding on tannin diets. - Can. Entomol. 123: $1047-1055$.

Campbell, B. C. and Duffey, S. S. 1979. Tomatine and parasitic wasps: potential incompatibility of plant antibiosis with biological control. - Science 205: 700-702.

Campbell, B. C. and Duffey, S. S. 1981. Alleviation of $\alpha$-tomatine-induced toxicity to the parasitoid, Hyposoter exiguae, by phytosterols in the diet of the host, Heliothis zea. - J. Chem. Ecol. 7: 927-946. 
De Moraes, C. M., Lewis, W. J., Paré, P. W. et al. 1998. Herbivore-infested plants selectively attract parasitoids. - Nature 393: 570-573.

Dicke, M., Sabelis, M. W. and Takabayashi, J. 1990a. Do plants cry for help? Evidence related to a tritrophic system of predatory mites, spider mites and their host plants. - Symp. Biol. Hung. 39: 127-134.

Dicke, M., Sabelis, M. W., Takabayashi, J. et al. 1990b. Plant strategies of manipulating predator-prey interactions through allelochemicals: prospects for application in pest control. - J. Chem. Ecol. 16: 3091-3118.

Duffey, S. S., Bloem, K. A. and Campbell, B. C. 1986. Consequences of sequestration of plant natural products in plant-insect-parasitoid interactions. - In: Boethel, D. J. and Eikenbary, R. D. (eds), Interactions of plant resistance and parasitoids and predators of insects. Ellis Horwood Limited, pp. 31-60.

Eben, A., Benrey, B., Sivinski, J. et al. 2000. Host species and host plant effects on preference and performance of Diachasmimorpha longicaudata (Hymenoptera: Braconidae). - Environ. Entom. 29: 87-94.

El-Heneidy, A. H., Barbosa, P. and Gross, P. 1988. Influence of dietary nicotine on fall armyworm, Spodoptera frugiperda and its parasitoid, the ichneumonid wasp Hyposoter annulipes. - Entomol. Exp. Appl. 46: 227-232.

Elliot, S. L., Sabelis, M. W., Janssen, A. et al. 2000. Can plants use entomopathogens as bodyguards? - Ecol. Lett. 3: $228-$ 235 .

Faeth, S. H. 1994. Induced plant responses: effects on parasitoids and other natural enemies of phytophagous insects. In: Hawkins, B. A. and Sheehan, W. (eds), Parasitoid community ecology. Oxford Univ. Press, pp. 245-260.

Fernald, M. L. 1950. Gray's manual of botany, 8th ed. - American Book Company.

Fox, L. R., Letourneau, D. K., Eisenbach, J. et al. 1990. Parasitism rates and sex ratios of a parasitoid wasp: effects of herbivore and plant quality. - Oecologia 83: 414-419.

Fox, L. R., Kester, K. M. and Eisenbach, J. 1996. Direct and indirect responses of parasitoids to plants: sex ratio plant quality and herbivore diet breadth. - Entomol. Exp. Appl. 80: 289-292.

Fukushima, J., Kainoh, Y., Honda, H. et al. 2002. Learning of herbivore-induced and nonspecific plant volatiles by a parasitoid, Cotesia kariyai. - J. Chem. Ecol. 28: 579-586.

Gauld, I. D. and Gaston, K. J. 1994. The taste of enemy-free space: parasitoids and nasty hosts. - In: Hawkins, B. A. and Sheehan, W. (eds), Parasitoid community ecology. Oxford Univ. Press, pp. 279-299.

Gómez, J. M. and Zamora, R. 1994. Top-down effects in a tritrophic system: parasitoids enhance plant fitness. - Ecology 75: 1023-1030.

Gorder, N. K. N. and Mertins, J. W. 1984. Life history of the parsnip webworm, Depressaria pastinacella (Lepidoptera: Oecophoridae), in central Iowa. - Ann. Entomol. Soc. Am. 77: $568-573$

Hardy, I. C. W. 1996. Precocious larvae in the polyembryonic parasitoid Copidosoma sosares (Hymenoptera: Encyrtidae). - Entomol. Bericht. 56: 88-92.

Hare, J. D. 1992. Effects of plant variation on herbivore-natural enemy interactions. - In: Fritz, R. S. and Simms, E. L. (eds), Plant resistance to herbivores and pathogens: ecology, evolution, and genetics. Univ. Chicago Press, pp. 278-298.

Hare, J. D. and Luck, R. F. 1991. Indirect effects of citrus cultivars on life history parameters of a parasitic wasp. - Ecology 72: 1576-1585.

Harvey, J. A., van Dam, N. M. and Gols, R. 2003. Interactions over four trophic levels: foodplant quality affects development of a hyperparasitoid as mediated through a herbivore and its primary parasitoid. - J. Anim. Ecol. 72: 520-531.

Hoballah, M. E. F., Tamò, C. and Turlings, T. C. J. 2002. Differential attractiveness of induced odors emitted by eight maize varieties for the parasitoid Cotesia marginiventris: is quality or quantity important? - J. Chem. Ecol. 28: 951 968.

Hodges, R. W. 1974. Gelechioidea Oecophoridae. - In: Dominick, B. B., Ferguson, D. C., Franclemont, J. G. et al. (eds), The moths of America north of Mexico. Fascicle 6.2

Kauffman, W. C. and Flanders, R. V. 1985. Effects of variably resistant soybean and lima bean cultivars on Pediobius foveolatus (Hymenoptera: Eulophidae), a parasitoid of the Mexican bean beetle, Epilachna varivestis (Coleoptera: Coccinellidae). - Environ. Entomol. 14: 678-682.

Kessler, A. and Baldwin, I. T. 2001. Defensive function of herbivore-induced plant volatile emissions in nature. - Science 291: 2141-2144.

Kruse, J. J. and Raffa, K. F. 1997. Effects of selected midwestern larval host plants on performance by two strains of the gypsy moth (Lepidoptera: Lymantriidae) parasitoid Cotesia melanoscela (Hymenoptera: Braconidae). - Environ. Entomol. 26: 1155-1166.

Larsson, S. and Ekbom, B. 1995. Oviposition mistakes in herbivorous insects: confusion or a step towards a new host plant. - Oikos 71: 155-160.

Lasota, J. A. and Kok, L. T. 1986. Residual effects of methomyl, permethrin, and fenvalerate on Pteromalus puparum (Hymenoptera: Pteromalidae) adult parasites. - J. Econ. Entomol. 79: 651-653.

Lingren, P. D., Wolfenbarger, D. A., Nosky, J. B. et al. 1972. Response of Campoletis perdistinctus and Apanteles marginiventris to insecticides. - J. Econ. Entomol. 65: 1295-1299.

van Loon, J. J. A., de Boer, J. G. and Dicke, M. 2000. Parasitoidplant mutualism: parasitoid attack of herbivore increases plant reproduction. - Entomol. Exp. Appl. 97: 219-227.

Marquis, R. J. 1992. Selective impact of herbivores. - In: Fritz, R. S. and Simms, E. W. (eds), Ecology and plant resistance to herbivores and pathogens. Univ. Chicago Press, pp. $301-$ 325.

Menemen, Y. and Jury, S. L. 2001. A taxonomic revision of the genus Pastinaca L. (Umbelliferae). - Isr. J. Plant Sci. 49: $67-77$.

Nitao, J. K. 1989. Enzymatic adaptation in a specialist herbivore for feeding on furanocoumarin-containing plants. - Ecology 70: 629-635.

Nitao, J. K. and Berenbaum, M. R. 1988. Laboratory rearing of the parsnip webworm, Depressaria pastinacella (Lepidoptera: Oecophoridae). - Ann. Entomol. Soc. Am. 81: 485487.

Nordlund, D. A., Lewis, W. J. and Altieri, M. A. 1988. Influences of plant-produced allelochemicals on the host/ prey selection behavior of entomophagous insects. - In: Barbosa, P. and le Tourneau, D. K. (eds), Novel aspects of insect-plant interactions. John Wiley \& Sons, pp. 65-90.

Nuttall, T. 1818. Genera of North American plants, vol. 1. - Reprinted in J. Ewan, ed. 1971. Classica Botanica Americana, vol. 7. Hafner Publishing Company.

Ode, P. J. and Strand, M. R. 1995. Progeny and sex allocation decisions of the polyembryonic wasp Copidosoma floridanum. - J. Anim. Ecol. 64: 213-224.

Orr, D. B. and Boethel, D. J. 1985. Comparative development of Copidosoma truncatellum (Hymenoptera: Encyrtidae) and its host, Pseudoplusia includens (Lepidoptera: Noctuidae), on resistant and susceptible soybean genotypes. - Environ. Entomol. 14: 612-616.

Orr, D. B., Boethel, D. J. and Jones, W. A. 1985. Biology of Telenomus chloropus (Hymenoptera: Scelionidae) from eggs of Nezara viridula (Hemiptera: Pentatomidae) reared on resistant and susceptible soybean genotypes. - Can. Entomol. 117: 1137-1142.

Price, P. W. 1986. Ecological aspects of host plant resistance and biological control: interactions among three trophic levels. - In: Boethel, D. J. and Eikenbary, R. D. (eds), Interactions of plant resistance and parasitoids and predators of insects. Ellis Horwood Limited, pp. 11-30. 
Price, P. W., Bouton, C. E., Gross, P. et al. 1980. Interactions among three trophic levels: influence of plants on interactions between insect herbivores and natural enemies. - Annu. Rev. Ecol. Syst. 11: 41-65.

Rathman, R. J., Johnson, M. W., Rosenheim, J. A. et al. 1992. Sexual differences in insecticide susceptibility and synergism with piperonyl butoxide in the leafminer parasitoid Diglyphus begini (Hymenoptera: Eulophidae). - J. Econ. Entomol. 85: 15-20.

Reed, D. K., Webster, J. A., Jones, B. G. et al. 1991. Tritrophic relationships of Russian wheat aphid (Homoptera: Aphididae), a hymenopterous parasitoid (Diaeretiella rapae McIntosh), and resistant and susceptible small grains. - Biol. Control 1: 35-41.

Reitz, S. R. and Trumble, J. T. 1996. Tritrophic interactions among linear furanocoumarins, the herbivore Trichoplusia $n i$ (Lepidoptera: Noctuidae), and the polyembryonic parasitoid Copidosoma floridanum (Hymenoptera: Encyrtidae). - Environ. Entomol. 25: 1391-1397.

Riggen, T. M., Isenhour, D. J. and Espelie, K. E. 1992. Effect of Cotesia marginiventris (Hymenoptera: Braconidae) when rearing host fall armyworm (Lepidoptera: Noctuidae) on meridic diet containing foliage from resistant or susceptible corn genotypes. - Environ. Entomol. 21: 214-219.

Rogers, D. J. and Sullivan, M. J. 1991. Development of Brachymeria ovata (Hymenoptera: Chalcididae) in three noctuid hosts reared on artificial diet and insect-resistant and susceptible soybean genotypes. - Entomophaga 36: 1927.

Roth, S., Knorr, C. and Lindroth, R. L. 1997. Dietary phenolics affects performance of the gypsy moth (Lepidoptera: Lymantriidae) and its parasitoid Cotesia melanoscela (Hymenoptera: Braconidae). - Environ. Entomol. 26: $668-671$.

Sabelis, M. W. and de Jong, M. C. M. 1988. Should all plants recruit bodyguards? Conditions for a polymorphic ESS of synomone production in plants. - Oikos 53: 247-252.

SAS Institute Inc. 1999-2001. SAS Proprietary Software Version 8.2. - SAS Institute Inc., Cary, North Carolina, USA.

Scott, J. G. and Rutz, D. A. 1988. Comparative toxicities of seven insecticides to house flies (Diptera: Muscidae) and Urolepis rufipes (Ashmead) (Hymenoptera: Pteromalidae). - J. Econ. Entomol. 81: 804-807.

Senrayan, R. and Annadurai, R. S. 1991. Influence of host's food plant and habitat on Anastatus ramakrishnae (Mani) (Hym., Eupelmidae), an egg parasitoid of Coridius obscurus (Fab.) (Het., Pentatomidae). - J. Appl. Entomol. 112: 237243.

Sheppard, A. W. 1991. Biological flora of the British Isles: Heracleum sphondylium L. - J. Ecol. 97: 235-258.

Smith, J. M. 1957. Effects of the food plant of California red scale, Aonidiella aurantii (Mask.) on reproduction of its hymenopterous parasites. - Can. Entomol. 89: 219-230.

Stamp, N. E. and Bowers, M. D. 1996. Consequences for plantain chemistry and growth when herbivores are attacked by predators. - Ecology 77: 535-549.

Stark, J. D., Wong, T. T. Y., Vargas, R. I. et al. 1992. Survival, longevity, and reproduction of tephritid fruit fly parasitoids (Hymenoptera: Braconidae) reared from fruit flies exposed to azadirachtin. - J. Econ. Entomol. 85: 1125-1129.

Strand, M. R., Baehrecke, E. H. and Wong, E. A. 1991. The role of host endocrine factors in the development of polyembryonic parasitoids. - Biol. Cont. 1: 144-152.

Takabayashi, J. and Dicke, M. 1996. Plant-carnivore mutualism through herbivore-induced carnivore attractants. - Trends Plant Sci. 1: 109-113.

Tiley, G. E. D., Dodd, F. S. and Wade, P. M. 1996. Biological flora of the British Isles: Heracleum mantegazzianum Sommier \& Levier. - J. Ecol. 84: 297-319.

Thaler, J. S. 1999. Jasmonate-inducible plant defences cause increased parasitism of herbivores. - Nature 399: 686-688.
Thompson, J. N. 1988. Evolutionary ecology of the relationship between oviposition preference and performance of offspring in phytophagous insects. - Entomol. Exp. Appl. 47: $3-14$.

Thompson, J. N. and Price, P. W. 1977. Plant plasticity, phenology, and herbivore dispersion: wild parsnip and the parsnip webworm. - Ecology 58: 1112-1119.

Thompson, J. N. and Pellmyr, O. 1990. Evolution of oviposition behavior and host preference in Lepidoptera. - Annu. Rev. Entomol. 36: 65-89.

Thorpe, K. W. and Barbosa, P. 1986. Effects of comsumption of high and low nicotine tobacco by Manduca sexta (Lepidoptera: Sphingidae) on survival of gregarious endoparasitoid Cotesia congregata (Hymenoptera: Braconidae). - J. Chem. Ecol. 12: 1329-1337.

Thurston, R. and Fox, P. M. 1972. Inhibition by nicotine of emergence of Apanteles congregatus from its host, the tobacco hornworm. - Ann. Entomol. Soc. Am. 65: 547550.

Turlings, T. C. J. and Benrey, B. 1998. Effects of plant metabolites on the behavior and development of parasitic wasps. - Écoscience 5: 321-333.

Turlings, T. C. J., Wäckers, F. L., Vet, L. E. M. et al. 1992. Learning of host-location cues by hymenopterous parasitoids. - In: Lewis, A. C. and Papaj, D. R. (eds), Insect learning: ecological and evolutionary perspectives. Chapman and Hall, pp. 51-78.

Turlings, T. C. J., Loughrin, J. H., Röse, U. et al. 1995. How caterpillar-damaged plants protect themselves by attracting parasitic wasps, Proc. Natl Acad. Sci. - USA 9: 4169-4174.

Vinson, S. B. 1984. Parasitoid-host relationships. - In: Bell, W. J. and Carde, R. (eds), Chemical ecology of insects. Sinauer Associates, pp. 205-233.

Vinson, S. B. 1999. Parasitoid manipulation as a plant defense strategy. - Ann. Entomol. Soc. Am. 92: 812-828.

Werren, J. H., Raupp, M. J., Sadoff, C. S. et al. 1992. Host plants used by gypsy moths affect survival and development of the parasitoid Cotesia melanoscela. - Envion. Entomol. 21: $173-177$.

Whitman, D. W. 1988. Allelochemical interactions among plants, herbivores, and their predators. - In: Barbosa, P. and le Tourneau, D. K. (eds), Novel aspects of insect-plant interactions. John Wiley \& Sons, pp. 11-64.

Whitman, D. W. and Nordlund, D. A. 1994. Plant chemicals and the location of herbivorous arthropods by their natural enemies. - In: Anathakrishnan, T. N. (ed.), Functional dynamics of phytophagous insects. Oxford and IBH Publishing, pp. 133-159.

Xu, J., Shelton, A. M. and Cheng, X. 2001. Variation in susceptibility of Diadegma insulare (Hymenoptera: Ichneumonidae) to permethrin. - J. Econ. Entomol. 94: 541-546.

Zangerl, A. R. and Berenbaum, M. R. 1990. Furanocoumarin induction in wild parsnip: genetics and populational variation. - Ecology 71: 1933-1940.

Zangerl, A. R. and Berenbaum, M. R. 1992. Oviposition patterns and hostplant suitability: parsnip webworms and wild parsnip. - Am. Midl. Nat. 128: 292-298.

Zangerl, A. R. and Berenbaum, M. R. 1993. Plant chemistry, insect adaptations to plant chemistry, and host plant utilization patterns. - Ecology 74: 47-54.

Zangerl, A. R. and Rutledge, C. E. 1996. The probability of attack and patterns of constitutive and induced defense: a test of optimal defense theory. - Am. Nat. 147: 599-608.

Zangerl, A. R. and Berenbaum, M. R. 1997. Costs of chemically defending seeds: furanocoumarins and Pastinaca sativa. - Am. Nat. 150: 491-504.

Zangerl, A. R. and Berenbaum, M. R. 2003. Phenotype matching in wild parsnip and parsnip webworms: causes and consequences. - Evolution 57: 806-815.

Zangerl, A. R., Arntz, A. M. and Berenbaum, M. R. 1997. Physiological price of an induced chemical defense: photosynthesis, respiration, biosynthesis, and growth. - Oecologia 109: 433-441. 
Zangerl, A. R., Green, E., Lampman, R. et al. 1997. Phenological changes in primary and secondary chemistry of reproductive parts of Pastinaca sativa. - Phytochemistry 44: 825-831.

Zangerl, A. R., Huang, T., McGovern, J. L. et al. 2002. Paradoxical host shift by Depressaria pastinacella in North
America: is enemy-free space involved? - Oikos 98: 431436.

Zvereva, E. L. and Rank, N. E. 2003. Host plant effects on parasitoid attack on the leaf beetle Chrysomela lapponica. - Oecologia 135: 258-267. 